\title{
Analysis on Wind Power System Reactive Power Optimization of Jiujiang Region Power Grid
}

\author{
Shunhua Zhang a , Zongyao Wang, Xiaopin Yang, Huijun Xu \\ School of Mechanical and Electrical Engineering, \\ Nanchang Institute Technology, \\ Nanchang 330099, China \\ athreehhu@163.com
}

\begin{abstract}
With the uncertainty and variability of wind, Wind turbines interconnection will change the original structure of the system and influence the power flow, the network loss and voltage stability of power grid. Therefore, a fast, practical calculation methods of the grid with wind power are in urgent need to make the system reactive power compensation economic and effective, the voltage regulation rapid and accurate. According to the characteristics of wind power system, this document present an improved genetic artificial fish algorithm which can quickly optimize the wind power system reactive power. The reactive power optimization results of Jiujiang Region power grid prove that this algorithm is effective.
\end{abstract}

Keywords-wind power system; reactive power optimization; genetic algorithm; improvement fish swarm algorithm

\section{INTRODUCTION}

In recent years, more and more new wind farms interconnect into power grid, the impact on power grid has also been widespread attention. Currently mostly wind is induction generator, this type of generator will absorb a large number of reactive power when the wind turbine interconnect to power grid, and reduce the stability of the system and power quality. At the same time, the output power of wind turbines is fluctuated according to the wind speed changes, the change of power and voltage are affected each other [1]. On the other hand, the stronger randomness of wind will cause a certain degree of influence for power generation and operation planning. Starting from studying the characteristics of the power output of wind turbines, the research for wind power system reactive power optimization has far-reaching significance [2]. With the increasing of wind power generating capacity, wind power has more and more influence to power grid. The wind power system reactive power optimization model and its algorithm play an important role to improve the wind power grid performance.The traditional planning scheme for the power fluctuation situation will no longer fit, this requires a new reactive power optimization scheme [3].

\section{THE MAIN RESEARCH METHODS}

\section{A. Mathematical Modeling}

The traditional model and algorithm of reactive power optimization is not fully applicable in the distribution network with wind power. The main reason is that wind power generators have very strong randomness and intermittent, under the condition of a certain wind power output of reactive power optimization, in other output state the optimization plan is not necessarily the optimal, sometimes is a kind of in-feasible solution. Artificial fish algorithm has a good ability to obtain the global extremum, but currently in wind power reactive power optimization, has not been specific effective application.

In view of the randomness and intermittent wind power generators, the paper combination genetic algorithm with artificial fish algorithm. The convergence and convergence speed of the algorithm was improved, at the same time the global search and local search performance were improved. To make the global search and local search, search efficiency and effect balance is the main purpose of this study.

\section{B. The Thesis Proposes an Improved Genetic Artificial Fish Swarm Algorithm}

In this paper,selection operator and the elite preservation strategy are introduced.It gets implementation of steady-state reproduction, i.e. Multi-optimal individuals in each generation does not participate in the crossover and mutation operations,directly copy them to the next generation group. In the remainder of the artificial fish individuals, draw out a certain number of artificial fish random, according to a certain probability of crossover operations on them. After the cross operation, the artificial fish individuals were set aside a certain individuals from the rest of artificial fish according to a certain probability of mutation operation. The operation of selection, crossover and mutation operation of artificial fish individuals are based on the optimization of the specific object to determine. This paper takes the distribution network expansion planning as the optimization object, the number of selection, crossover and mutation operation of artificial fish are less, there are quite a number of artificial fish individuals do not need to take any action, directly into the next generation population.

Genetically improved artificial fish swarm algorithm improve the artificial fish quality, at the same time, maintain and increase the diversity of artificial fish populations, so a part of the artificial fish are searched in a region, a part of the artificial fish jump out the local extremum and into the other space field search new local 
extremum,the performance of the algorithm is improved comprehensive.

\section{The Objective Function is Established}

The optimization model of reactive power compensation is designed to calculate the reactive power compensation capacity to meet the optimal power constraints and other operating variables constraints. So the minimum network loss is taken as the objective function of [4], considering the influence of node voltage and generator in the reactive power output of cross-border, the cross-border voltage is processed on the node voltage violation and generator by penalty function [5]

$$
\begin{aligned}
\min F= & \sum_{i \in N, j \in I} G_{i j}\left(U_{i}^{2}+U_{j}^{2}-2 U_{i} U_{j} \cos \theta_{i j}\right)+ \\
& \lambda_{1} \sum_{i \in \alpha}\left(\frac{U_{i}-U_{i \lim }}{U_{i}^{\max }-U_{i}^{\min }}\right)^{2}+\lambda_{2} \sum_{i \in \beta}\left(\frac{Q_{i}-Q_{i l \lim }}{Q_{i}^{\max }-Q_{i}^{\min }}\right)^{2}
\end{aligned}
$$

In Eq. $1, \lambda_{1}$ and $\lambda_{2}$ are the penalty factor in violation of voltage constraints and generator reactive power output constraints. $N$ is the number of node. $I$ is the number of branch, $\alpha$ and $\beta$ are respectively the collection for the violation of nodes voltage constraints and node in violation of generator reactive power constraints of, $U_{\text {ilim }}$ and $Q_{\text {ilim }}$ are respectively voltage and the reactive power limits of motor node.

The algorithm is applied to the distribution power system with wind turbines, the existing $110 \mathrm{kV}$ power grid in Jiujiang area and four wind farms(Jishan Lake, Changling, Daling, Laoyemiao) simulation. By the end of 2012, Jiujiang power grid has a public. The number of $110 \mathrm{kV}$ substation is 41 , the number of main transformer is
66 , the total capacity is 2289 MVA. The number of $110 \mathrm{kV}$ special substation is 17 , the number of main transformer is 28 , the total capacity is $685 \mathrm{MVA}$, the number of $110 \mathrm{kV}$ public line is 86 , total length is $1285.478 \mathrm{~km}$, the number of $110 \mathrm{kV}$ special line is 15 , total length is $250.365 \mathrm{~km}$. 2012 Jiujiang power supply region of the $110 \mathrm{kV}$ grid size table in table I.

TABLE I. 2012 JIUJIANG POWER SUPPLY REGION OF THE 110KV GRID SIZE TABLE

\begin{tabular}{|c|c|c|}
\hline Project & Public grid & Special grid \\
\hline $110 \mathrm{kV}$ substation & 41 & 17 \\
\hline $110 \mathrm{kV}$ main transformer & 66 & 28 \\
\hline $110 \mathrm{kV}$ total capacity (MVA) & 2289 & 685 \\
\hline $110 \mathrm{kV}$ line & 86 & 15 \\
\hline $110 \mathrm{kV}$ length (km) & 1285.478 & 250.365 \\
\hline $110 \mathrm{kV}$ capacity load ratio & 2.09 & 2.20 \\
\hline
\end{tabular}

Improved genetic artificial fish swarm algorithm, artificial fish swarm algorithm, particle swarm algorithm are applied to Jiujiang $110 \mathrm{kV}$ main power grid reactive power optimization calculation, and after comparison and analysis, to adjust control measures, so that the off-limits node voltage are returned to the control range, the optimization node voltage of three algorithms comparison is shown in table II, optimized reactive compensation capacity of all nodes are shown in table III.

\begin{tabular}{|c|c|c|c|c|c|}
\hline Node & $\begin{array}{c}\text { The node voltage before } \\
\text { improveme-nt }\end{array}$ & $\begin{array}{c}\text { The node voltage after } \\
\text { improveme-nt }\end{array}$ & Node & $\begin{array}{c}\text { The node voltage before } \\
\text { improveme-nt }\end{array}$ & $\begin{array}{c}\text { The node voltage after } \\
\text { improvem-ent }\end{array}$ \\
\hline $\begin{array}{l}\text { Jiujiang power } \\
\text { plant(II) }\end{array}$ & 0.989739 & 0.9899 & $\begin{array}{l}\text { Jiujiang power } \\
\text { plant(III) }\end{array}$ & 0.989725 & 0.9897 \\
\hline $\begin{array}{l}\text { Dongjing power } \\
\text { plant }\end{array}$ & $\begin{array}{c}1.056002 \\
\text { off-uplimit }\end{array}$ & 0.9743 & Baozishi power plant & 0.980927 & 0.9806 \\
\hline $\begin{array}{l}\text { Changling wind } \\
\text { power }\end{array}$ & $\begin{array}{c}1.002845 \\
\text { off-uplimit }\end{array}$ & 0.9783 & Xiafang power plant & 0.991763 & 0.9917 \\
\hline $\begin{array}{l}\text { Daling wind } \\
\text { power(II) }\end{array}$ & $\begin{array}{c}1.002744 \\
\text { off-uplimit }\end{array}$ & 0.9714 & Jishan Lake wind power & $\begin{array}{l}1.002369 \\
\text { off-uplimit }\end{array}$ & 0.9746 \\
\hline $\begin{array}{l}\text { Shacheng } \\
\text { substation }\end{array}$ & 0.9874653 & 0.9875 & $\begin{array}{l}\text { Miaozhi } \\
\text { substation }\end{array}$ & $\begin{array}{l}1.0001342 \\
\text { off-uplimit }\end{array}$ & 0.9923 \\
\hline Gongqing substation & $\begin{array}{c}1.001547 \\
\text { off-uplimit }\end{array}$ & 0.9886 & $\begin{array}{l}\text { Shizhongshan } \\
\text { substation }\end{array}$ & 0.9965632 & 0.9899 \\
\hline
\end{tabular}

TABLE II. THE OPTIMIZATION NODE VOLTAGE OF THREE ALGORITHMS COMPARISON (P.U. ) 
TABLE III. OPTIMIZED REACTIVE CAPACITY COMPENSATION OF ALL NODES (MVAR)

\begin{tabular}{|c|c|c|c|c|c|}
\hline Node & $\begin{array}{c}\text { The compensation } \\
\text { capacity before } \\
\text { improveme-nt }\end{array}$ & $\begin{array}{c}\text { The compensation } \\
\text { capacity after } \\
\text { improveme-nt }\end{array}$ & Node & $\begin{array}{c}\text { The compensation } \\
\text { capacity before } \\
\text { improveme-nt }\end{array}$ & $\begin{array}{c}\text { The compensation } \\
\text { capacity after } \\
\text { improveme-nt }\end{array}$ \\
\hline $\begin{array}{l}\text { Jishan Lake } \\
\text { wind power }\end{array}$ & 2 & 3 & $\begin{array}{l}\text { Shacheng } \\
\text { substation }\end{array}$ & 6 & 8 \\
\hline $\begin{array}{c}\text { Changling wind } \\
\text { power }\end{array}$ & 4 & 5 & $\begin{array}{l}\text { Gongqing } \\
\text { substation }\end{array}$ & 8 & 9.5 \\
\hline $\begin{array}{c}\text { Daling wind } \\
\text { power(II) }\end{array}$ & 2 & 2.5 & $\begin{array}{l}\text { Miaozhi } \\
\text { substation }\end{array}$ & 7 & 7 \\
\hline $\begin{array}{l}\text { Laoyemiao } \\
\text { wind power }\end{array}$ & 1.5 & 1.5 & $\begin{array}{c}\text { Shizhongshan } \\
\text { substation }\end{array}$ & 8 & 9 \\
\hline
\end{tabular}

The convergent curves of three kinds of are shown in Figure $1.110 \mathrm{kV}$ main power grid net loss was $3.02 \%$. In the picture, the number of iterations of three optimization algorithms are very different.

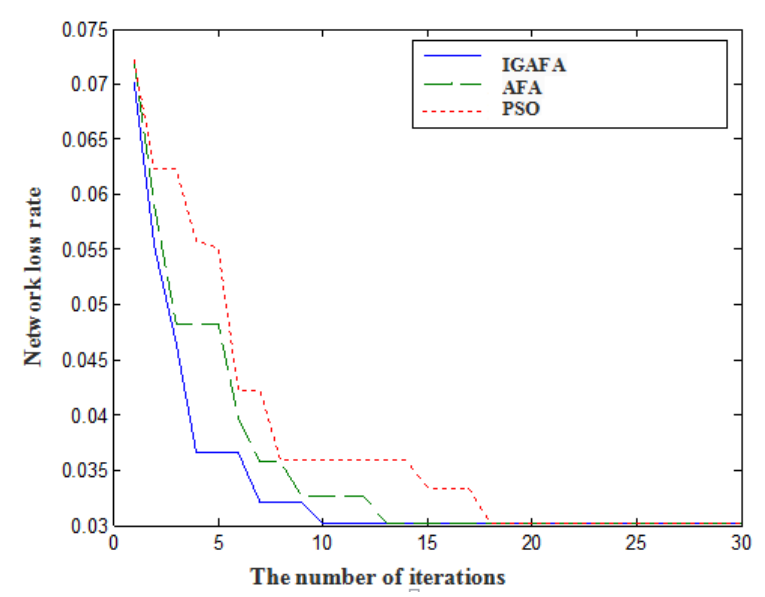

Figure 1. Three kinds of algorithm convergence curve contrast

Improved genetic artificial fish swarm algorithm(IGAFA) is better than the artificial fish swarm algorithm(AFA) and particle swarm algorithm(PSO)in the rate of convergence. The results of optimization prove that the improved genetic artificial fish algorithm is feasible.

\section{SUMMARY}

After improved genetic artificial fish swarm algorithm optimization, the grid node voltage keep under control in this group operation data, and the electric network loss rate has fallen about $0.48 \%$. The power grid is a dynamic system, according to the different operation conditions, the reactive power compensation is also different.According to the electric network loss rate dropping $0.3 \%$ each year, the grid company will get direct economic benefits about 6.0524 million yuan every year, economic benefit is very considerable.

Through mathematical modeling, algorithm fusion to improve the existing artificial fish algorithm and improve optimization, improved genetic artificial fish swarm algorithm containing ability was significantly high in reactive power optimization for wind power system.

\section{ACKNOWLEDGMENT}

This work was financially supported by the Jiangxi Natural Science Foundation (20114BAB206036), the Science and Technology Project of Jiangxi Province Education Department (GJJ13769).

\section{CORRESPONDING AUTHOR}

Shunhua Zhang (1972 -), associate professor, master degree, research direction: power system operation and control.

Email: threehhu@163.com, Mobile phone: 13870802685

\section{REFERENCES}

[1] Ming Ding, Min Wang, in: Distributed power generation technology [J]. Electric power automation equipment, 2004, 4(7): 31-36.

[2] Zhiqun Wang, Shouzhen Zhu, in: The influence of distributed generation on distribution network voltage distribution [J]. Automation of electric power systems, 2004,28(16): 56-60.

[3] Min Hu, Renjun Zhou, in: Considering wind power system reactive power optimization model and algorithm [J]. Journal of Changsha university of science and technology, 2009,6(1):43-48.

[4] Jun Luo, in: Including wind turbines of the reactive power optimization of distribution network research [D], Hunan university, 2009.

[5] Yanli Zhang, in: Wind farm reactive power compensation based on ant colony algorithm [D]. Beijing Jiaotong university, 2009. 